\title{
In Situ Formation of Gold-“Decorated" Vesicles from a RAFT-Synthesized, Thermally Responsive Block Copolymer"
}

\author{
Yuting Li ${ }^{\dagger}$, Adam E. Smith ${ }^{\dagger}$,Brad S. Lokitz ${ }^{\dagger}$, and Charles L. McCormick ${ }^{\dagger, \S^{*}}$
}

${ }^{\dagger}$ Department of Polymer Science and ${ }^{\S}$ Department of Chemistry and Biochemistry, University of Southern Mississippi,

Hattiesburg, Mississippi 39406-0076 (USA)

\section{Experimental Section}

General Procedure for the RAFT Polymerization of DMAEMA: A solution of 4-cyanopentanoic acid dithiobenzoate $\quad(\mathrm{CTP}) \quad(0.0177 \mathrm{~g}, \quad 0.0637 \mathrm{mmol}), \quad$ DMAEMA $\quad(2.00 \mathrm{~g}, \quad 12.7$ mmol$), \quad$ and 4,4'-Azobis(4-cyanopentanoic acid) (V-501, Wako Chemicals) $(0.00354 \mathrm{~g}, 0.0127 \mathrm{mmol})$ in $6.5 \mathrm{~mL}$ of dioxane were added to a $25 \mathrm{~mL}$ ampoule. The solution was sparged with nitrogen for approximately $30 \mathrm{~min}$ and the ampoule placed in a preheated oil bath at $70{ }^{\circ} \mathrm{C}$. The reaction was terminated after $8 \mathrm{~h}(69 \%$ conversion) by cooling the reaction tube in an ice bath followed by exposure to air. The product $\left({ }^{1} \mathrm{H}\right.$ NMR shown in Figure 2A) was purified by precipitation into heptane.

Block Copolymer Synthesis. NIPAM (0.294 g, 2.00 mmol), PDMAEMA (0.10g), and V-501 (0.381 mg, $0.00137 \mathrm{mmol}$ ) were dissolved in $1 \mathrm{~mL}$ of dioxane were added to a $10 \mathrm{~mL}$ ampoule. After sparging with nitrogen for $30 \mathrm{~min}$, the reaction was allowed to proceed at $80{ }^{\circ} \mathrm{C}$ for $6 \mathrm{~h}$ (42\% conversion). The reaction was then quenched by cooling the reaction vessel in an ice bath and exposure to air. The product $\left({ }^{1} \mathrm{H}\right.$ NMR shown in Figure 2B) was purified by dialysis against deionized water and isolated by lyophilization.

Polymer Characterization. The molecular weights of the (co)polymers were determined using Viscotek-TDA (302 RI (633 nm), $7 \mathrm{~mW} 90^{\circ}$ and $7^{\circ}$ true low angle light scattering detectors, $\lambda=670 \mathrm{~nm}$ ) size exclusion chromatography (SEC) equipped with two Polymer Labs PLgel $5 \mu \mathrm{m} \quad(30 \mathrm{~cm})$ Mixed "C" columns $(200-2,000,000 \mathrm{~g} / \mathrm{mol})$ at $60{ }^{\circ} \mathrm{C}$. The mobile phase consisted of HPLC grade DMF. The flow rate was maintained at $0.5 \mathrm{~mL} \min ^{-1}$ using an Agilent 1100 series pump. The molecular weight and polydispersity data were determined using the OmniSEC software package (version 2,0,2,89). SEC traces 
for the PDMAEMA macroCTA and the PDMAEMA $73-b$-PNIPAM 99 are shown in Figure S1. ${ }^{1} \mathrm{H}$ NMR spectra were measured for (co)polymer dissolved in $\mathrm{D}_{2} \mathrm{O}$ using a temperature controlled Mercury Innova $500 \mathrm{MHz}$ spectrometer.

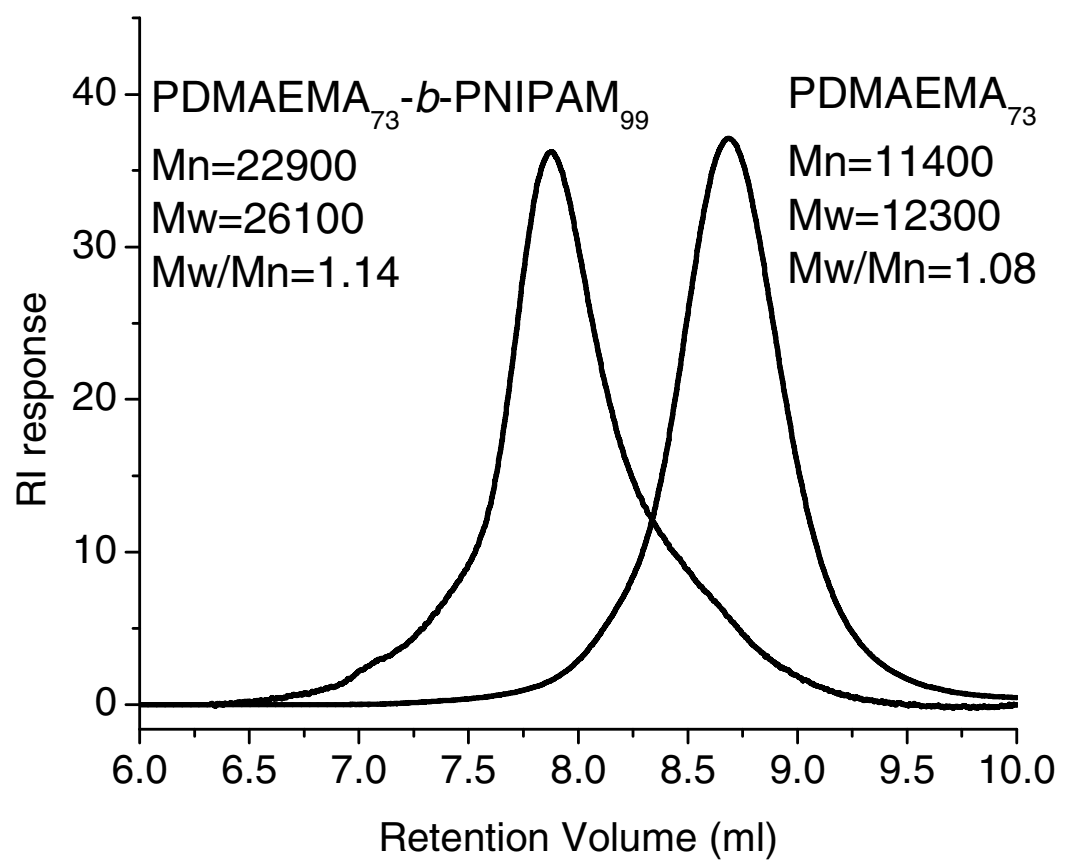

Figure S1: DMF SEC traces for (a) the PDMAEMA homopolymer, (b) PDMAEMA $73-b$-PNIPAM99 diblock copolymer.

Gold Nanoparticle-Containing Vesicle Preparation. PDMAEMA ${ }_{73}-b$-PNIPAM $99(0.0015 \mathrm{~g})$ was dissolved in $15 \mathrm{~mL}$ DI water, the solution was then heated to $50{ }^{\circ} \mathrm{C}$ for the vesicle formation. After $30 \mathrm{~min}, 1 \mathrm{~mL}$ $(0.5 \mathrm{mM})$ of sodium tetrachloroaurate (III) dihydrate solution $\left(\mathrm{NaAuCl}_{4}\right)$ at $\mathrm{pH} 6.5$ was added to the vesicle solution at $50{ }^{\circ} \mathrm{C}$. The mixed solution was kept at $50{ }^{\circ} \mathrm{C}$ for 48 hours prior to analysis with DLS and TEM (Figure 4). As a control experiment, a $0.01 \mathrm{wt} \%$ aqueous solution of PDMAEMA $73-b$-PNIPAM 99 was mixed with $1 \mathrm{~mL}(0.5 \mathrm{mM})$ of $\mathrm{NaAuCl}_{4}$ solution and allowed to stir at $25{ }^{\circ} \mathrm{C}$ for 2 days prior to dynamic light scattering (DLS) and transmission electron microscopy (TEM) analysis (Figure S3).

Characterization of Particles. DLS measurements (Figure S2) of the block copolymer solution (0.01 wt $\%$ in water), gold nanoparticle-containing vesicles, and polymer-grafted gold nanoparticles were conducted with a Malvern Instruments Zetasizer Nano series instrument equipped with a $4 \mathrm{~mW}$ He-Ne 
laser operating at $\lambda=632.8 \mathrm{~nm}$, an avalanche photodiode detector with high quantum efficiency, and an ALV/LSE-5003 multiple tau digital correlator electronics system. Zeta potential measurements (Figure S3) were performed on an aqueous $0.01 \mathrm{wt} \%$ copolymer solution using a Malvern Instruments Zetasizer Nano series instrument using the Smoluchowsky relationship. The solution $\mathrm{pH}$ was adjusted by the addition of $0.1 \mathrm{M} \mathrm{HCl}$ or $0.1 \mathrm{M} \mathrm{NaOH}$. Transmission electron microscopy (TEM) measurements were conducted using a JEOL JEM-2100 electron microscope at an acceleration voltage of $200 \mathrm{kV}$. The specimens were prepared by placing a drop of either the gold nanoparticle-containing vesicle (Figure 4a) or the polymer-grafted nanoparticle (Figure S4) solution on a carbon-coated copper grid followed by water evaporation at $25{ }^{\circ} \mathrm{C}$.

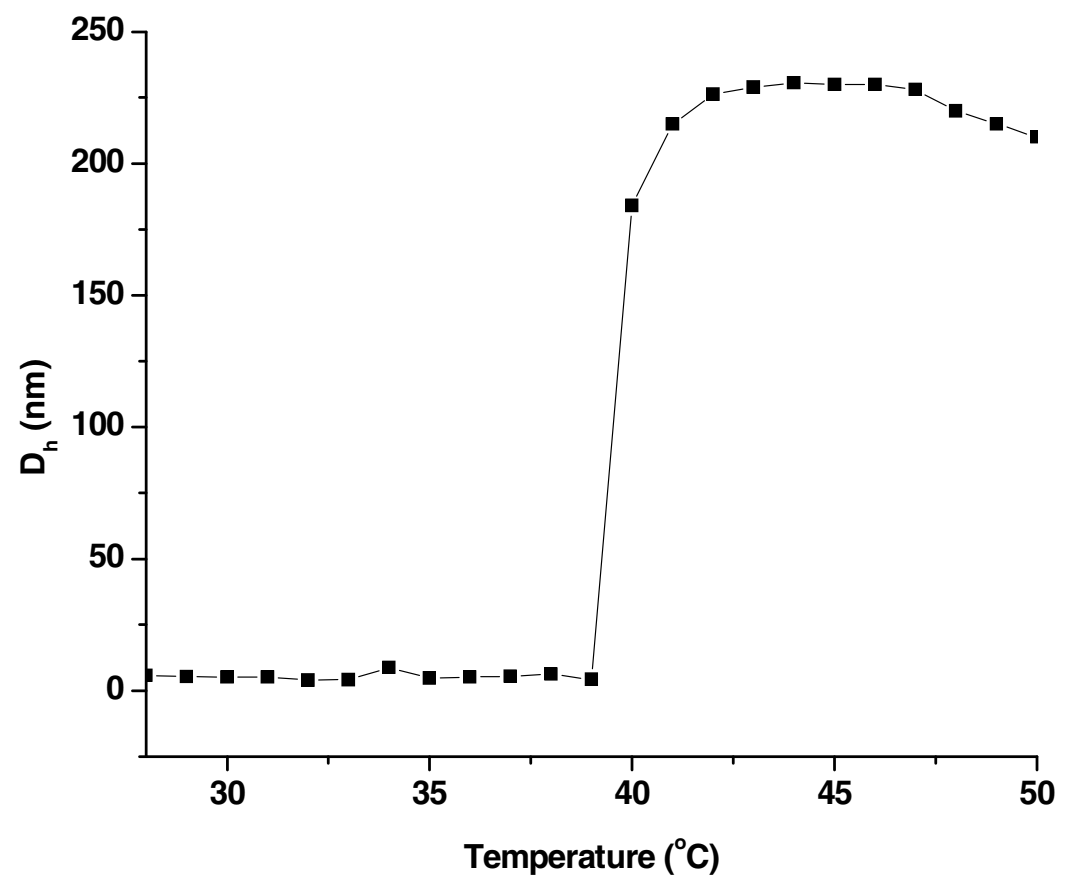

Figure S2. Variation of hydrodynamic diameter with temperature for the PDMAEMA $73-b$-PNIPAM 99 diblock copolymer at $0.01 \mathrm{wt} \%$ in aqueous solution at $\mathrm{pH}$ 7.4. 


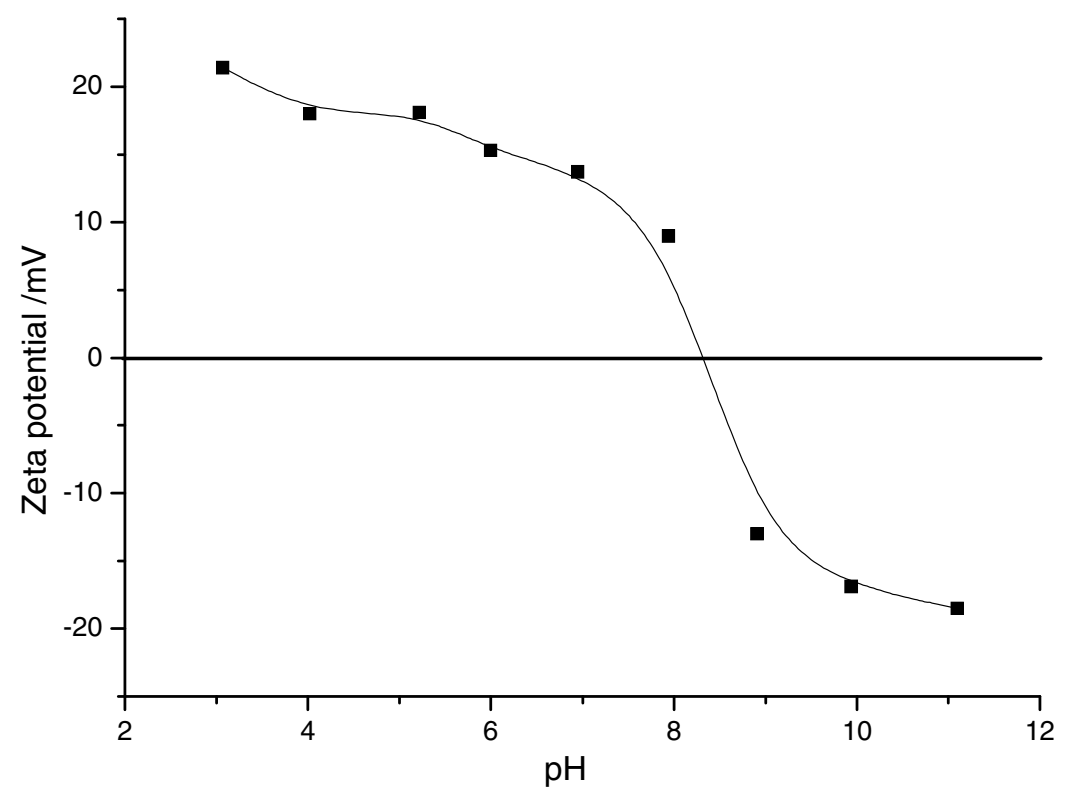

Figure S3: Zeta potential vs $\mathrm{pH}$ curves obtained for the vesicles self-assembled from PDMAEMA $_{73}-b-$ PNIPAM $_{99}$ diblock copolymer.

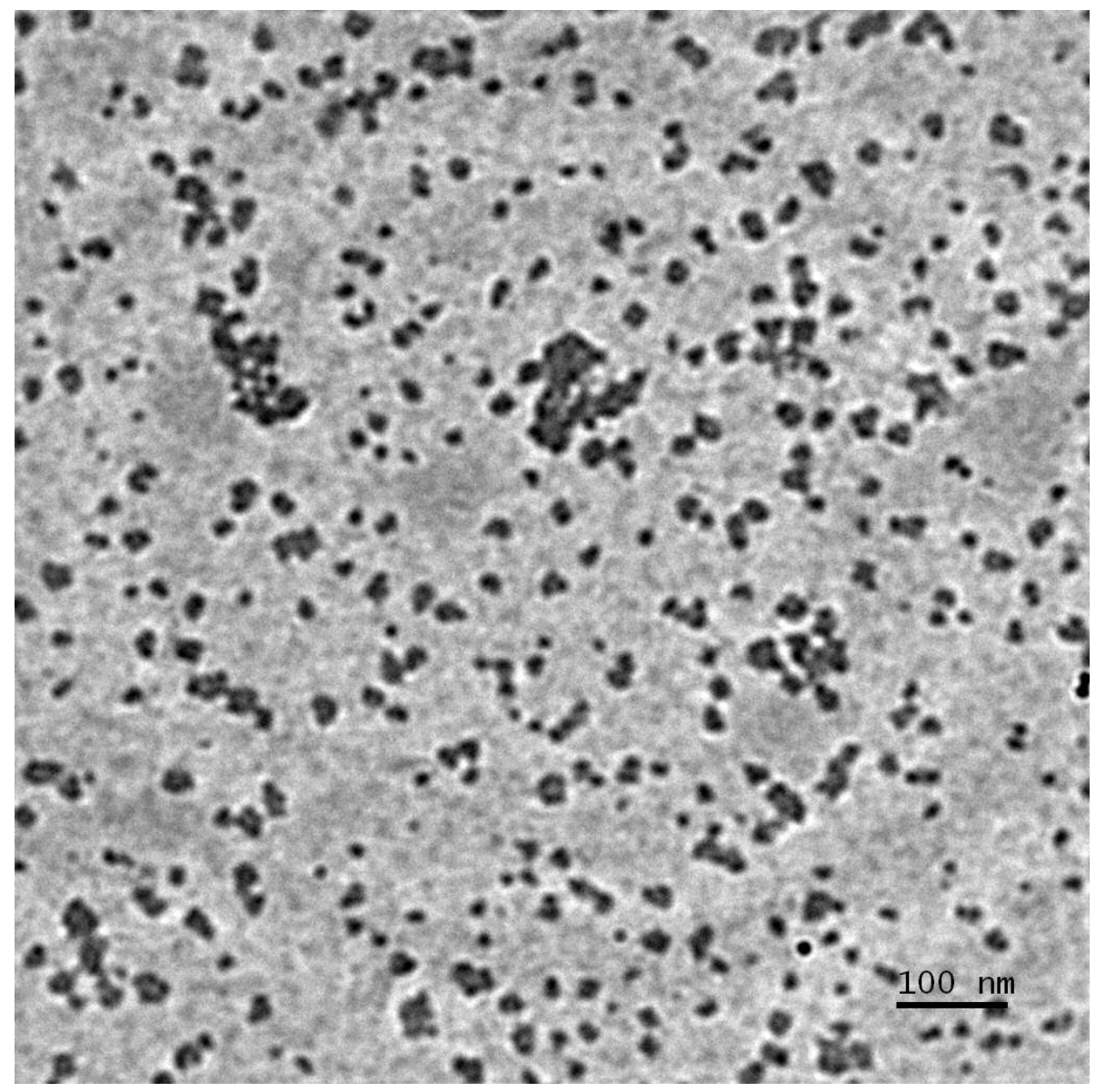

Figure S4: Transmission electron micrograph of the control experiment PDMAEMA ${ }_{73}-b-$ PNIPAM $_{99}$ stabilized gold nanoparticles formed at $25{ }^{\circ} \mathrm{C}$. 